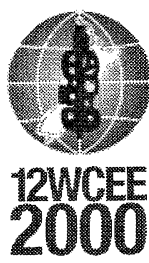

2831

\title{
PERFORMANCE BASED SEISMIC DESIGN
}

\author{
M J N PRIESTLEY ${ }^{1}$
}

\begin{abstract}
SUMMARY
One of the major developments in seismic design over the past 10 years has been increased emphasis on limit states design, now generally termed Performance Based Engineering. Three techniques - the capacity spectrum approach, the N2 method and direct displacement-based design have now matured to the stage where seismic assessment of existing structures, or design of new structures can be carried out to ensure that particular deformation-based criteria are met.

The paper will outline and compare the three methods, and discuss them in the context of traditional force-based seismic design and earlier design approaches which contained some elements of performance based design. Factors defining different performance states will be discussed, including the need, not yet achieved, to include residual displacement as a key performance limit. Some emphasis will be placed on soil-related problems, and the incorporation of soil/structure interaction into performance-based design. It will be shown that this is relatively straightforward and results in consistent design solutions not readily available with force-based designs using force-reduction factors.
\end{abstract}

\section{INTRODUCTION}

Design for seismic resistance has been undergoing a critical reappraisal in recent years, with the emphasis changing from "strength" to "performance". For most of the past 70 years - the period over which specific design calculations for seismic resistance have been required by codes - strength and performance have been considered to be synonymous. However, over the past 25 years there has been a gradual shift from this position with the realisation that increasing strength may not enhance safety, nor necessarily reduce damage. The development of capacity design principles in New Zealand in the 1970's (Park and Paulay, 1976) was an expression of the realisation that the distribution of strength through a building was more important than the absolute value of the design base shear. It was recognised that a frame building would perform better under seismic attack if it could be assured that plastic hinges would occur in beams rather than in columns (weak beam/strong column mechanism), and if the shear strength of members exceeded the shear corresponding to flexural strength. This can be identified as the true start to performance based seismic design, where the overall performance of the building is controlled as a function of the design process.

As an understanding developed in the 1960s and 1970s of the importance of inelastic structural response to large earthquakes, the research community became increasingly involved in attempts to quantify the inelastic deformation capacity of structural components. Generally this was expressed in terms of displacement ductility capacity, $\mu_{\Delta}$, which was chosen as a useful indicator because of its apparent relationship to the force-reduction factor, $\mathrm{R}$, commonly used to reduce expected elastic levels of base shear strength to acceptable design levels. As is seen in Fig. 1(a), the equal displacement approximation of seismic response implies that:

$$
\mu_{\Delta}=\mathrm{R}
$$


There have been problems with this approach, in that is has long been realised that the equal displacement approximation is inappropriate for both very short and very long period structures, and is also of doubtful validity for medium period structures when the hysteretic character of the inelastic system deviates significantly from elasto-plastic. Further, there has been difficulty in reaching consensus within the research community as to the appropriate definition of yield and ultimate displacements. With reference to Fig. 1(b), the yield displacement has been variously defined as the intersection of the initial tangent stiffness with the nominal strength, the intersection of the secant stiffness through first yield with nominal strength, and the displacement at first yield, amongst other possibilities. Displacement capacity, or ultimate displacement, has also had a number of definitions, including displacement at peak strength, displacement corresponding to $20 \%$ or $50 \%$ degradation from peak (or nominal) strength, and displacement at initial fracture of transverse reinforcement. Clearly with such a wide choice of limit displacements, there has been considerable variation in the assessed displacement ductility capacity of structures.

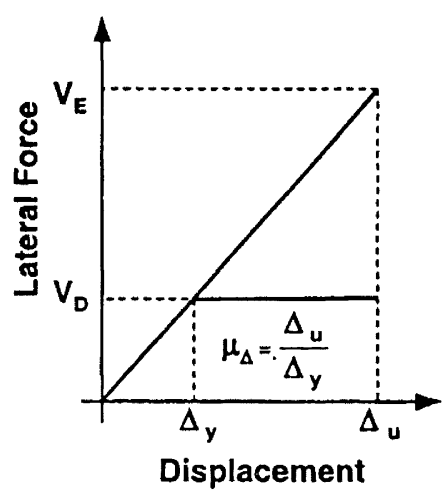

(a) Equal Displacement Approximation

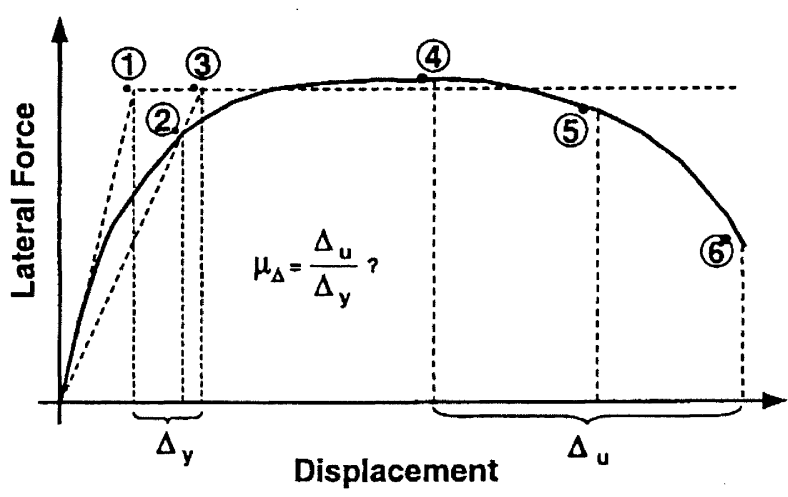

(b) Definition of Yield and Ultimate Displacement

Figure 1: Problems With Definition of Ductility Capacity

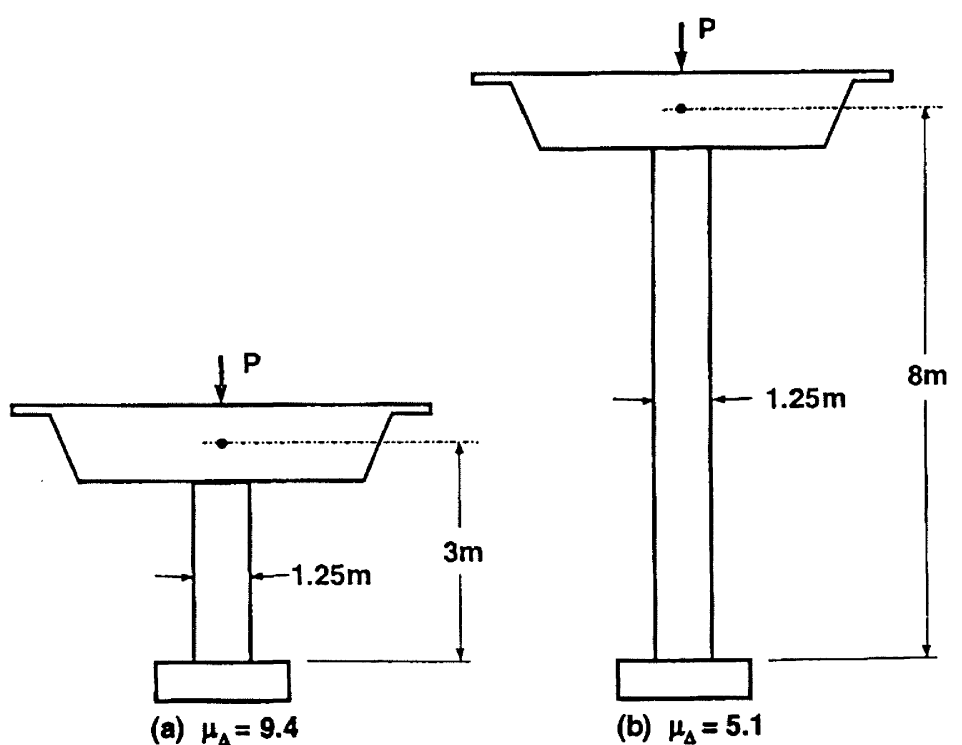

Figure 2: Influence of Height on Displacement Ductility Capacity of Circular Bridge Piers $\left(P=0.1 f_{e}^{\prime}, A_{2} \rho_{L}=0.02, \rho_{1}=0.006\right)$

Implicit in the force-reduction factor approach to determination of required strength is the assumption that particular structural systems can be allocated characteristic ductility capacities, and hence characteristic force reduction factors. It has, however, become apparent over the past 15 years, that is an unacceptable approximation. Ductility capacity of concrete and masonry structures depends on a wide range of factors, including axial load ratio, reinforcement ratio, and structural geometry. Foundation compliance also can 
significantly affect the displacement ductility capacity. These aspects were discussed in relation to bridge structures in a summary paper (Priestley and Park, 1985), which advocated specific calculation of the displacement capacity of bridge substructures, based on estimates of ultimate strain capacity, plastic hinge length, and foundation conditions. This approach has been widely used in New Zealand since the mid 1980s, and has more recently been adopted into US design recommendations (ATC, 1996). An example of the influence of structure geometry on displacement ductility capacity is provided in Fig. 2 (Kowalsky, 1995), which compares the ductility capacity of two bridge columns with identical cross sections, axial loads and reinforcement details, but with differing heights. The calculated displacement ductility capacity of the two columns differ by a factor of two, as a consequence of the plastic hinge length, and hence the plastic rotation, being only weakly dependent on the column height, while the elastic drift ratio is directly proportional to height.

Moehle (1992) later suggested a similar approach to that of Priestley and Park (1985), for building structures. These approaches recognise some of the imperfections of a pure force-based design, by requiring calculation of the ductility capacity of structures, and checking this against estimates of the ductility demand corresponding to the design level of seismicity and force reduction factor adopted for design. In New Zealand and Europe this is still considered to be force-based design, while in the US the addition of the displacement check, possibly with modification of the design strength as a consequence of the displacement check, has come to be known as displacement-based design, or performance-based design.

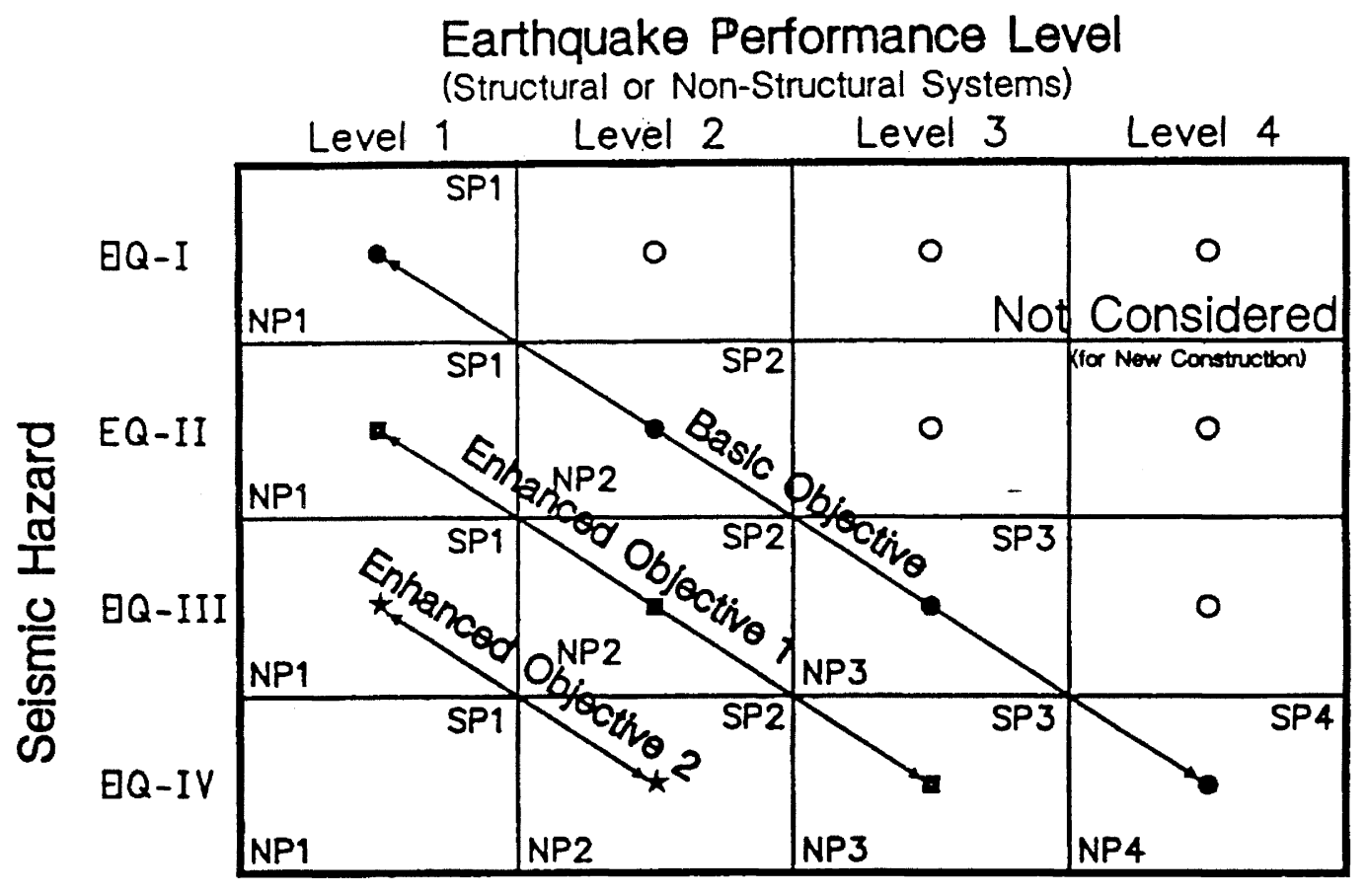

Figure 3: Relationship between earthquake design level and performance level (after OES, 1995)

\section{ALTERNATIVE DESIGN PROCEDURES}

The re-examination of the fundamental precepts of seismic design has intensified in recent years, with a great number of conflicting approaches being advocated. In some cases the differences between the approaches are fundamental, while in others the differences are conceptual. A crucial catalyst for this interest has been the Vision 2000 document, (OES, 1995) prepared by the Structural Engineers Association of California. The core of this document is the selection of "seismic performance objectives" defined as the "coupling of expected performance level with expected levels of seismic ground motions". Four performance levels are defined: 
- Fully Operational. Facility continues in operation with negligible damage.

- Operational. Facility continues in operation with minor damage and minor disruption in nonessential services.

- Life Safe. Life safety is substantially protected, damage is moderated to extensive.

- Near Collapse. Life safety is at risk, damage is severe, structural collapse is prevented.

The relationship between these performance levels and earthquake design level is summarised in Fig. 3 (OES, 1995).

\subsection{Conceptual Considerations Related to Performance Levels}

It would appear that the gap between "Occupancy" and "Life Safety" performance levels might be too large, while that between "Life Safety" and "Collapse" might be too small. Concern was expressed by a number of participants that some form of "Damage Control" performance level, related to damage cost be defined. Drawing on experience with the repair of buildings after the 1995 Kobe earthquake, Otani, (Otani, 1997) noted that although frame buildings designed in accordance with the weak-beam/strong-column philosophy survived the earthquake without collapse, the cost of repairing the many locations of inelastic action, and hence localised damage, was often excessive, and uneconomic. Alternative structural systems with fewer locations of inelastic action, as might occur in structural wall buildings were more economical in terms of repair costs. Otani also raised the possibility of acceptance of ductile soft-storey mechanisms protected against shear failure by capacity design principles and excessive local ductility demand as a possible attractive approach in terms of reduced repair costs.

The need to consider repair costs in definition of a design performance level was echoed by Poland and Hom, (Poland and Hom 1997) who emphasised the need to include business interruption costs in the equation.

Kawashima (Kawashima, 1997), also drawing on lessons from the 1995 Kobe earthquake, drew attention to the need to consider residual deformation in defining the damage control performance level. Consideration of residual deformation is explicitly required in the 1996 Japanese seismic design specifications for bridges (JRA, 1996). This is clearly an important consideration, but it is felt that more research based on realistic hysteretic rules and real earthquake records will be needed before reliable residual displacement spectra are available.

An interesting development at the workshop was the comparatively low profile given to energy methods and cumulative damage models. Cosenza and Manfredi (Cosenza and Manfredi, 1997) noted that cumulative damage criteria are very important for poorly designed existing structures, but of lesser importance for welldesigned modern structures. Similar considerations have been reached by a CEB work group on Seismic Design issues (CEB, 1996).

\subsection{Assessment and Verification Procedures}

Although there was wide-spread agreement that inelastic time-history analysis had the greatest potential for accurate verification of seismic performance of designed structures, there was also agreement that the method was not yet mature enough for use by the general design profession. As a consequence, much of the emphasis at the workshop was on simpler assessment approaches, generally based on push-over analysis. Fajfar (Fajfar et al, 1997) provided an update on the N2 method which has been under development at the University of Ljubljana for the past 12 years. In this approach, an estimate of the seismic displacement demand is found by response spectrum analysis of an equivalent single-degree-of-freedom (SDOF) bilinear model, representing the first elastic mode of the structure. This displacement demand is compared with the results of a push-over analysis of a multi-degree-of-freedom (MDOF) representation of the structure under a force vector compatible with an assumed displacement profile. From the limit to displacement imposed by the calculated displacement demand, local inelastic deformations are extracted from the push-over analysis, and hence, via Park-Ang damage models, local and global damage indices are determined.

A very similar procedure known as the capacity spectrum method, developed by Freeman (Freeman, 1998) over the past 15 years, was referenced by a number of researchers at the workshop. The main differences from the N2 method appear to be that damage indices are not specifically referenced in the Capacity Spectrum approach, and that seismic demand is expressed in terms of a response spectra set plotted with acceleration on the vertical axis, and displacement on the horizontal axis. Period is determined by radial lines from the origin. This convenient representation enables the demand and the capacity (expressed as a push-over curve) to be plotted on the same 
graph. Some manipulation to the push-over curve is required to transform it to an equivalent SDOF model. An example is shown in Fig. 4(a), with different demand curves shown for different levels of elastic damping. The procedure requires that the appropriate level of equivalent elastic damping be interpreted from the ductility demand. Fajfar (1998) has recently combined the two approaches, but using inelastic spectra, related to displacement-ductility demand, rather than equivalent viscous damping (see Fig. 4(b)). This presumes that the shape of the hysteretic response of the structure is irrelevant, or requires some modification to the demand for structures with non-structural hysteretic response.

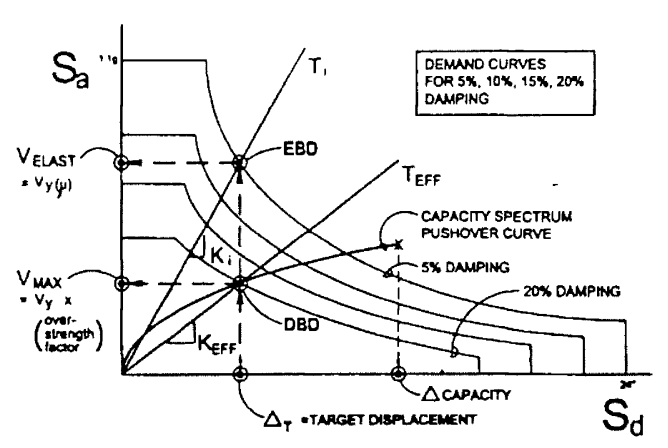

(a) Related to damping

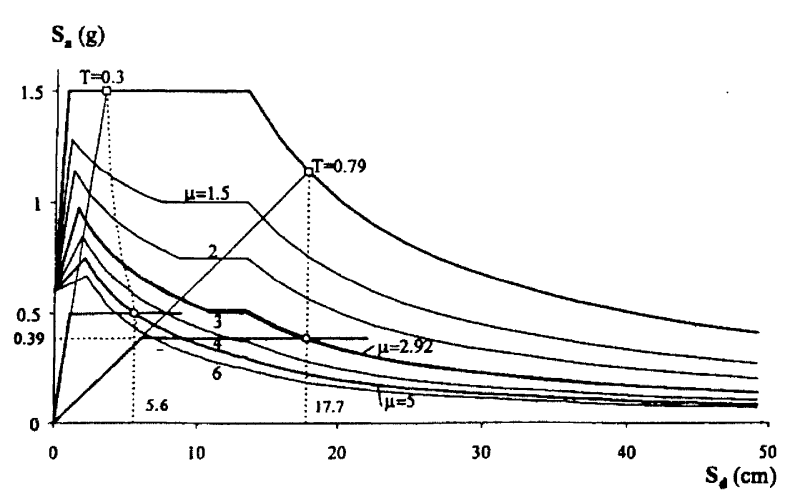

(b) Related to Ductility

Figure 4: The Capacity Spectrum Method

\subsection{Design Approaches}

Also writing in the Proceedings of the Bled Workshop, Kappos (1997) provides a useful summary of performance-based design approaches aimed at reducing local damage or ductility. He notes that Bertero and Zagajeski (1979) and Fintel and Ghosh (1982) proposed force-based code design for preliminary strength determination, with inelastic time-history analyses to check inelastic deformation. Successive "optimization" of design was proposed to reduce inelastic deformation at all locations to acceptable limits. A similar approach was suggested by Hatamoto et al (1990) and Stone and Taylor (1994) for buildings and bridges respectively, but using local damage indices rather than inelastic deformation as the acceptance criteria. Kappos (1997) observes that the computational effort involved in the successive approximation implied by these methods may be excessive, but also notes that the reliance on a simple SDOF model for initial design may be too simplistic, particularly when modern design codes generally require 3-D modal analysis as the starting point for required strength. He proposes a modified form of these approaches, where, for frames, beam strength is based on forces reduced from modal elastic analysis, using code force-reduction factors, with column strength being based on the results of inelastic time-history analyses using code spectrum-compatible accelerograms. A number of possible loading combinations are required when biaxial response is significant, as in two-way frames. Capacity design principles are then employed to determine required shear strength of members and joints. The time-history analyses are also used to check that storey drifts, and local inelastic deformations are within acceptable limits.

The procedure proposed by Kappos might reduce some of the potential conservatism associated with capacity design of columns, though it is the author's view that consequent savings are likely to be minimal. It is also not clear that a MDOF modal analysis is a better starting point than a simple SDOF model for ductile structures, since it is clear that inelastic action primarily reduces the force levels associated with the first mode, while having comparatively minor effect on the higher modes. Thus a force-based design approach which applies a constant force-reduction factor to all modes is likely to greatly underestimate the importance of higher modes. This is implicitly accounted for in simplified capacity design procedures (Paulay and Priestley, 1992).

Fardis and Panagiotakos (1997) suggest a simplified design procedure very similar to that required by the New Zealand Loadings Code (SANZ, 1994), but with a definition of the serviceability level earthquake, for which seismic design forces for ductile elements are calculated, based on an interpretation of the consequences of the gross-section stiffness required by EC8 $($ EC8, 1994). This leads to a force-reduction factor of 5, applied to the full design elastic forces, and implies rather similar results to the New Zealand approach, which utilises more realistic estimates of initial member stiffness. Fardis and Panagiotakos present results indicating that simple 
elastic analysis under a triangular lateral acceleration distribution will provide adequate estimates of storey drift, provided these are based on member stiffness at first yield.

\section{DIRECT DISPLACEMENT-BASED DESIGN}

It is apparent that the various procedures outlined above all advocate only minor changes to existing design approaches, and in fact do not advance beyond procedures which have been incorporated in the New Zealand Loadings Code for many years. It is contended that these are still force-based procedures, with the addition of a displacement check to ensure that acceptable performance levels are achieved in the design earthquake. It is emphasised that this is a perfectly acceptable design approach that can be expected to result in safe structures, but that it does not directly address performance criteria at the initial stage of the design. There are also some conceptual and philosophical problems associated with force-based/displacement-check design:

- As noted earlier, the use of characteristic force-reduction or ductility factors for design results in nonuniform risk, since ductility is a poor indicator of damage potential. Thus two different buildings designed to the same code and with the same force-reduction or ductility factors may experience different levels of damage under a given earthquake. This seems philosophically incompatible with the use of uniform-risk design spectra.

- For many, if not most structures, code drift limits will be found to govern, when realistic values are used for stiffness in displacement checks. As a consequence, force-reduction factors will be less than code indicative limits. This implies the need for iterative design, and increased design complexity.

- Increasing emphasis is placed in recent issues of seismic design codes on 3-D modal analysis. As noted earlier, this underestimates the influence of higher mode effects, unless response is essentially elastic, and implies the need for capacity design. If capacity design is required, there seems little benefit from the additional complexity of 3-D modal analysis.

- As has been conclusively demonstrated by Paulay (Paulay, 1997), design based on force-reduction factors provides an inadequate representation of torsional effects, underestimating the torsional response for ductile torsionally unrestrained systems (those without torsional resistance in the direction orthogonal to that under consideration), while overestimating the torsional response of ductile torsionally restrained systems. It would thus seem that the apparent increase in structural characterisation resulting from 3-D analysis is largely illusory.

- It is generally accepted that damage is strain related (for structural components), or drift related (for non-structural components). There is no clear relationship between strength and damage. This is also obvious from point 1 above.

- $\quad$ Force-based design requires the specification of initial stiffness of structural members, unless simplified, and outdated height-based formulae for building period are used, as in UBC-97. Even then forces are distributed between structural members on the basis of initial stiffness. This is sometimes taken to be gross stiffness, and sometimes as a reduced stiffness to represent the influence of cracking, in concrete and masonry structures. This implies that the structural stiffness is independent of strength, for a given gross member dimension, and that yield displacement, or yield curvature is directly proportional to strength, as shown in Fig. 5(a). Detailed analyses, and experimental evidence show that this assumption is invalid, in that stiffness is essentially directly proportional to strength, and the yield displacement or curvature is essentially independent of strength, as shown in Fig. 5(b). It has been found possible to express the yield curvature of different reinforced concrete structural members by the following dimensionless relationships (Priestley and Kowalsky, 1998; Priestley, 1998(b)): 
Beams (rectangular or flanged)

$$
\begin{array}{ll}
\mathrm{h}_{\mathrm{b}} \varphi_{\mathrm{y}}=1.70 \varepsilon_{\mathrm{y}} & \pm 10 \% \\
\mathrm{D} \varphi_{\mathrm{y}}=2.35 \varepsilon_{\mathrm{y}} & \pm 15 \% \\
\mathrm{~h}_{\mathrm{c}} \varphi_{\mathrm{y}}=2.12 \varepsilon_{\mathrm{y}} & \pm 10 \% \\
\mathrm{l}_{\mathrm{w}} \varphi_{\mathrm{y}}=2.00 \varepsilon_{\mathrm{y}} & \pm 10 \%
\end{array}
$$$$
\text { Circular columns: }
$$$$
\text { Rectangular walls: }
$$

where $h_{b}, D, h_{c}$ and $l_{w}$ are the beam depth, column diameter, column depth and wall length of the sections, and $\varepsilon_{y}=f_{y} / E_{s}$ is the yield strain of the longitudinal reinforcement in the section.

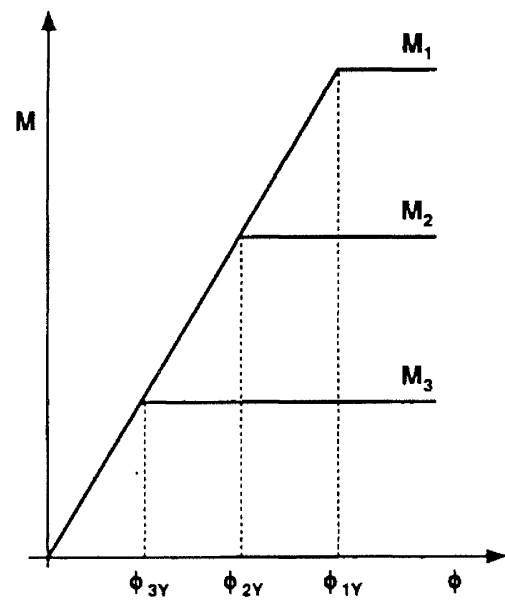

(a) Design Assumption (constant stiffness)

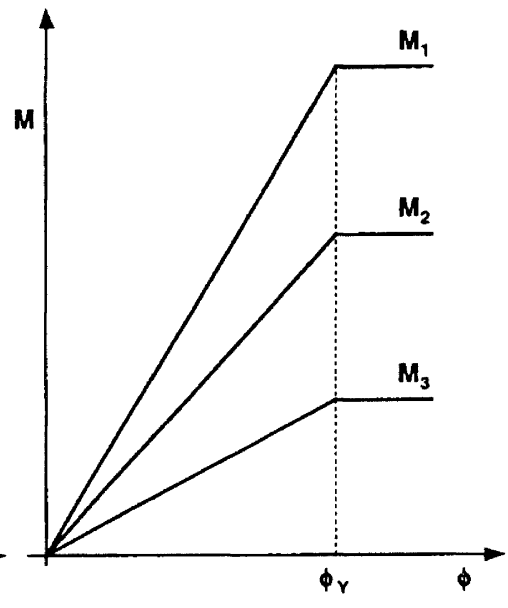

(b) Realistic Conditions (constant yield curvature)

Figure 5: Influence of Strength on Moment-Curvature Relationship

It was further shown (Priestley, 1998(b)) that the storey yield drift $\theta_{\mathrm{y}}$ of reinforced concrete frames could be expressed in the form:

$$
\theta_{\mathrm{y}}=0.5 \varepsilon_{\mathrm{y}} \mathrm{l}_{\mathrm{b}} / \mathrm{h}_{\mathrm{b}}
$$

where $l_{b}$ is the beam bay length. Calibrating equation (3) against experimental results from more than 40 beam-column test units showed surprisingly little scatter, with the mean experiment/prediction ratio being 1.03 , with a $16 \%$ coefficient of variation.

As a consequence of these findings it is not possible to perform an accurate analysis of either the structural period, nor of the elastic distribution of required strength through the structure, until the member strengths have been defined. Since these aspects are the fundamental basis for force-based design, the implication is that successive iteration must be carried out before an adequate elastic characterisation of the structure is obtained.

- The assumption that the elastic characteristics of the building are the best indicator of inelastic performance, as implied by force-based design, is clearly of doubtful validity. It is contended that the only reason that we cling to this approach is historical - seismic design started on the basis of simple elastic analysis in the 1930s, and the appreciation that it is displacement capacity, rather than strength that is more fundamental to seismic performance has not been general for sufficient time for the fundamental basis of seismic design, namely initial stiffness characterisation, to have been clearly examined and discarded.

It should be clear from the above that for force-based seismic design to be adequately incorporated into performance-based criteria, significantly increased design effort, in the form of successive iteration of the initial elastic characteristics must be required. At the same time, it is clear that increasing the computational effort of design, by requiring 3-D elastic analysis, is not likely to result in better characterisation of structural response than more simplified SDOF representations, unless structural response is essentially elastic. As a consequence of these considerations, an alternative design procedure known as "direct displacement-based design" has been 
developed (Priestley (1992), Priestley and Calvi (1997), Priestley and Kowalsky (2000)), that attempts to recognise deficiencies in the current force-based approaches, and to characterise the structure by a SDOF representation of performance at peak displacement response.

It would appear that a design approach that attempts to design a structure which would achieve, rather than be bounded by, a given performance limit state under a given seismic intensity would be desirable. This would essentially result in uniform-risk structures, which is philosophically compatible with the uniform-risk seismic intensity incorporated in most codes. Note that force-based design does not attempt to produce uniform risk structures, but attempts to keep the risk for a given structure below an acceptable threshold, albeit undefined. It can easily be shown that risk, in terms of annual probability of a given level of damage, for structures designed to force-based criteria, can vary by more than an order of magnitude from structure to structure.

While force-based design characterises a structure in terms of elastic properties (stiffness, damping) appropriate at first yield, direct displacement-based design characterises the structure by secant stiffness $\mathrm{K}_{\mathrm{e}}$ at maximum displacement $\Delta_{\mathrm{d}}$ (Fig. 6(b)) and a level of equivalent viscous damping appropriate to the hysteretic energy absorbed during inelastic response. Thus, as shown in Figure 6(c), for a given level of ductility demand, a structural steel building with compact members will be assigned a higher level of equivalent viscous damping than a reinforced concrete structural wall building designed for the same level of ductility demand, as a consequence of "fatter" hysteresis loops. The approach used to characterise the structure is based on the "substitute structure" analysis procedure developed by Shibata and Sozen (Shibata and Sozen, 1976).

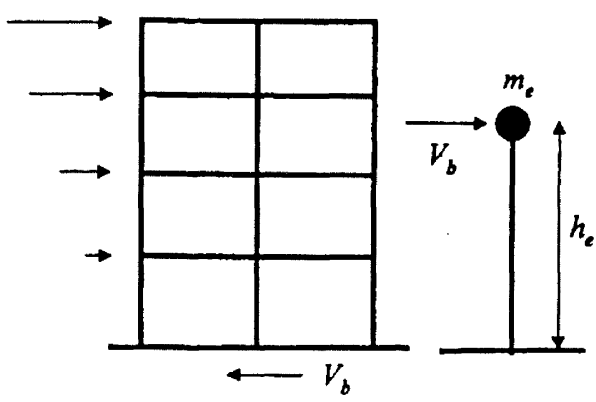

(a) SDOF Simulation

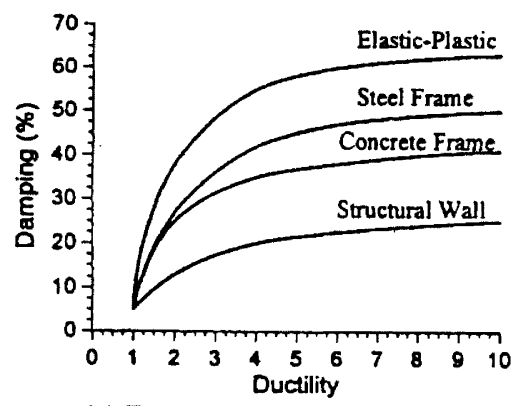

(c) Equivalent damping vs. ductility

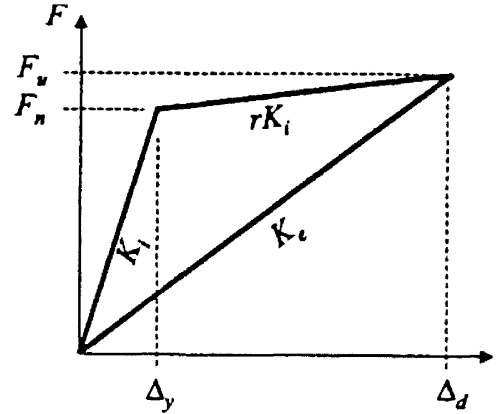

(b) Effective stiffness, $K_{e}$

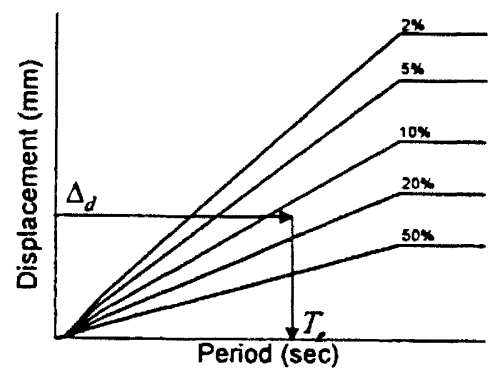

(d) Design displacement response spectra

Figure 6: Fundamentals of Direct Displacement-Based Design

With the design displacement $\Delta_{\mathrm{d}}$ determined, as discussed subsequently, and the damping estimated from the expected ductility demand, the effective period $T_{e}$ at maximum displacement response can be read from a set of design displacement spectra, as shown in the example of Figure 6(d). Representing the structure (Fig. 6(a)) as an equivalent SDOF oscillator, the effective stiffness $\mathrm{K}_{\mathrm{e}}$ at maximum response displacement can be found by inverting the equation for natural period of a SDOF oscillator, namely:

$$
\mathrm{T}_{\mathrm{e}}=2 \pi \sqrt{\frac{\mathrm{M}_{\mathrm{e}}}{\mathrm{K}_{\mathrm{e}}}}
$$


to provide

$$
\mathrm{K}_{\mathrm{e}}=4 \pi^{2} \mathrm{~m}_{\mathrm{e}} / \mathrm{T}_{\mathrm{e}}^{2}
$$

where $m_{e}$ is the effective mass.

From Figure 6(b), the design base shear at maximum response is thus:

$$
\mathrm{V}_{\mathrm{B}}=\mathrm{K}_{\mathrm{e}} \Delta_{\mathrm{d}}
$$

The design concept is thus very simple, and such complexity as exists relates to determination of the "substitute structure" characteristics, determination of the design displacement and development of design displacement spectra.

\subsection{Performance Limit States}

It is contended that two performance limit states should be considered. In terms of the previous discussion of the VISION 2000 approach (OES, 1995), these would be the Fully operational and the Damage Control performance limits. The latter would be somewhere between the Operational and Life Safe performance limits, and would depend on importance and function of the structure.

Crushing of concrete and unacceptably large residual crack widths might define the Fully operational limit state for concrete and masonry structures. Note that it is the residual crack width, rather than the maximum occurring during seismic response which is of principal interest. Limit compression strains of 0.004 would appear to be conservative and reasonable for both concrete and masonry. Maximum reinforcement tensile strains of 0.01 for beams and 0.015 for columns and walls seem appropriate, since analysis of test data indicates that residual crack widths of reinforced concrete members subjected to peak strains of this level will be in the range of $0.5-1.0 \mathrm{~mm}$.

The definition of a fully operational drift limit is less obvious, since the onset of non-structural damage is very dependent on the design details provided to separate non-structural elements from structural elements. More work is required in this area. However, with good detailing non-structural damage should not be evident at drifts of less than $\theta=0.01$.

The damage-control limit state can also be defined by material strain limits and by design drift limits intended to restrict non-structural damage. For example, a limit compression strain for confined concrete of:

$$
\varepsilon_{\mathrm{cm}}=0.004+1.4 \rho_{\mathrm{s}} \mathrm{f}_{\mathrm{yh}} \varepsilon_{\mathrm{suh}} / \mathrm{f}_{\mathrm{cc}}^{\prime}
$$

is felt to be conservative, where the confinement reinforcement has volumetric ratio $\rho_{\mathrm{s}}$, yield strength $\mathrm{f}_{\mathrm{yh}}$ and strain at maximum stress $\varepsilon_{\text {suh }}$, and $f_{\underline{c c}}$ is the compression strength of the confined concrete (Priestley et al, 1996).

The maximum longitudinal reinforcement tensile strain $\varepsilon_{\mathrm{sm}}$ must be limited to a lesser value than the strain $\varepsilon_{\mathrm{su}}$ at maximum stress to avoid buckling and low cycle fatigue. It is suggested that:

$$
\varepsilon_{\mathrm{sm}}=0.6 \varepsilon_{\mathrm{su}}
$$

It is comparatively straightforward to compute drift limits from strain limits. For example, and with reference to Fig. 7, the maximum drift corresponding to material strain limits will be the lesser of:

and

$$
\theta_{\mathrm{mc}}=\theta_{\mathrm{y}}+\left(\varepsilon_{\mathrm{cm}} / \mathrm{c}-\varphi_{\mathrm{y}}\right) \mathrm{l}_{\mathrm{p}} \quad \text { (concrete compression) }
$$

$$
\theta_{\mathrm{ms}}=\theta_{\mathrm{y}}+\left(\varepsilon_{\mathrm{sm}} /(\mathrm{d}-\mathrm{c})-\varphi_{\mathrm{y}}\right) \mathrm{l}_{\mathrm{p}} \quad \text { (reinforcement tension) }
$$

where $\theta_{\mathrm{y}}$ is the yield drift, and $l_{\mathrm{p}}$ the plastic hinge length.

The material drift limits of Equation 9 would be compared with the code drift limits imposed to limit nonstructural damage, and the more critical adopted for design. In almost all reinforced concrete structures, whether designed with walls or frames, it is likely to be the code drift limits that control the design drift. 


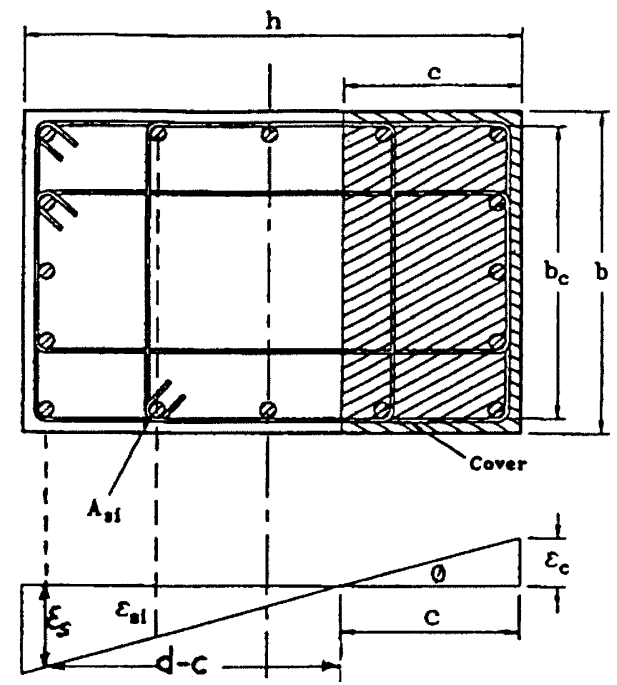

Figure 7: Strain Profile for a Rectangular Section

\subsection{Design Displacement Spectra}

A major difference from force-based design is that design utilises a set of displacement-period spectra (eg, Fig. 1(c)) for different levels of equivalent viscous damping, rather than the acceleration-period spectra for a $5 \%$ damping adopted by most force-based codes. Since the structural period of the substitute structure is longer than that for the elastic structure (ie, $T_{e}=V_{\mu} T_{i}$, where $T_{i}$ is the initial, elastic period), it is necessary for the displacement spectra to continue to longer periods than commonly plotted for acceleration spectra. It is also appropriate to place a cap on peak response displacements, since at long periods, structural displacements tend to reduce, eventually equaling the peak ground displacement. The European seismic code $(E C 8,1994)$ adopts a cap at $\mathrm{T}=3 \mathrm{sec}$. above which displacements are considered to be independent of period. Geotechnical considerations indicate that the cap period should depend on the foundation condition, with lower periods applying for rock than for soft soil.

Figure 8 shows displacement spectra derived from New Zealand code acceleration spectra for different soil conditions and a peak effective ground acceleration of $0.4 \mathrm{~g}$. Spectra for other than $5 \%$ damping have been determined using the EC8 modification factor of:

$$
\Delta_{(r .5)}=\Delta_{(r . s)}\left(\frac{7}{2+\xi}\right)^{1 / 2}
$$

where $\xi$ is the damping, expressed as a percentage of critical damping, for the design limit state being considered.

Based on this, it appears reasonable, and within the level of uncertainty inherent in formulation of design spectra, to adopt linear displacement spectra. The small non-linearity at low periods is unlikely to be significant for displacement-based designs, since it is the longer period at peak response that is of relevance.

Note that it would also be possible, and reasonable to express the design spectra in terms of capacity spectra (see Fig. 4); an approach adopted by the Structural Engineers Association of California (SEAOC, 1999) which recommends direct displacement-based design combined with capacity spectra. However, there are difficulties in extracting the period accurately from the capacity spectra, and the effective linearity of conventional displacement response spectra enable the sequence of design steps described above to be combined into a simple design equation for base shear. Let $\Delta_{\mathrm{p}, 5}$ be the displacement at cap period (eg, $\mathrm{T}_{\mathrm{p}}=4 \mathrm{sec}$ ) for displacement, corresponding to 5\% damping. From Equation 10, the corresponding displacement at $\mathrm{T}_{\mathrm{p}}$ for $\xi \%$ damping is: 


$$
\Delta_{(6, S)}=\Delta_{(6, s)}\left[\frac{7}{2+\xi}\right]^{\beta}
$$

For a design displacement of $\Delta_{\mathrm{d}}$, and design damping $\xi$, the effective period at peak response is thus

$$
T_{0}=T_{p} \frac{\Delta_{d}}{\Delta_{p} s}\left[\frac{2+\xi}{7}\right]^{p / 2}
$$

and, from Equation (5), the effective stiffness at peak response is:

$$
K_{e}=\frac{4 \pi^{2} m_{d}}{T_{p}^{2}} \frac{\Delta_{p, s}^{2}}{\Delta_{d}^{2}}\left[\frac{7}{2+\xi}\right]
$$

Finally, from Equation (6):

$$
V_{B}=\frac{4 \pi^{2} m_{G}}{T_{p}^{2}} \frac{\Delta_{p, 5}^{2}}{\Delta_{d}}\left[\frac{7}{2+\xi}\right]
$$

\subsection{Equivalent Single-Degree-of Freedom Model (substitute structure)}

\subsubsection{Effective Displacement}

It is evident from the previous discussion that the design procedure requires initial determination of the design displacement, and the effective mass and damping of the equivalent SDOF substitute structure.

In many cases, the design displacement will be dictated by code drift limits, as previously discussed. In general, however, the peak drift can be expressed as:

$$
\theta_{\mathrm{d}}=\theta_{\mathrm{y}}+\theta_{\mathrm{p}} \leq \theta_{\mathrm{c}}
$$

where the design drift $\theta_{\mathrm{d}}$ is comprised of elastic $\left(\theta_{\mathrm{y}}\right)$ and plastic $\left(\theta_{\mathrm{p}}\right)$ components and must not exceed the code limit $\theta_{\mathrm{c}}$. The critical location for $\theta_{\mathrm{d}}$ is likely to at the lower floors of a frame building, and the top floor of a structural wall building. In the latter case this refers to non-structural influence only. The critical condition for strain-related performance limits will be the wall base. For illustrative reasons, and because of space limitations, only the damage control limit state will be considered in the following. For frame structures, the elastic yield drift is given by Equation 3 and the plastic drift by:

$$
\theta_{p}=\left(\phi_{m}-\phi_{y}\right) \ell_{p} \cdot\left[\frac{l_{c}}{l_{d}}\right]
$$

where $\varphi_{m}$ is the critical curvature from Equation $9(a)$ or $9(b)$ and $l_{c}$ and $l_{b}$ are the clear beam length between column faces and the beam length from column centre to centre respectively. In many cases it will be more appropriate to select a design ductility limit of $\mu=\left(\theta_{y}+\theta_{p}\right) / \theta_{y}$ based on the extensive research data base of beam/column joint subassemblage testing, rather than calculate the plastic curvature based on an estimated plastic hinge length $l_{p}$, and an estimated maximum curvature. In this case, Equation 15 simplifies to: 


$$
\theta_{\mathrm{d}}=\mu \theta_{\mathrm{y}} \leq \theta_{\mathrm{c}}
$$

Based on the research data base, values in the range $4 \leq \mu \leq 6$ appear appropriate for well detailed beam plastic hinges. It is again emphasised, however, that unless the frames are unusually deep-membered, and low strength reinforcement is used, then the code drift limit will govern (Priestley, 1998(b)).
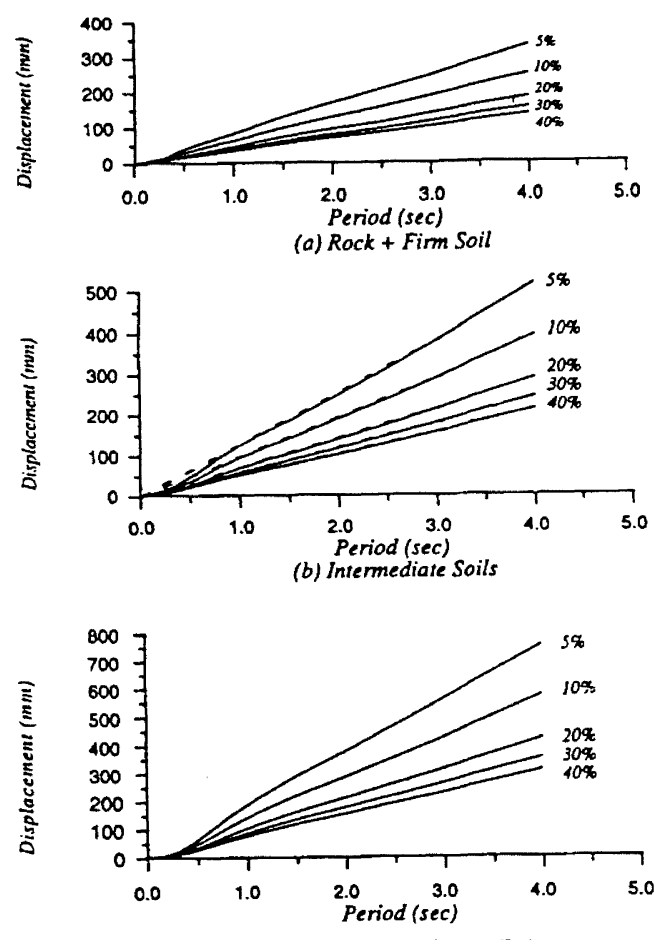

(c) Flexible or deep soil sites

\section{Figure 8: Design Displacement Spectra to NZS 4203/1992 and Equation 10}

Having determined the critical drift, the design displacements $\Delta_{\mathrm{i}}$ at different storeys (i) can be estimated from characteristic displacement profiles at maximum response based on elastic time history analysis. The following equations, though approximate, have been shown to be adequate for design purposes. (Loeding et al, 1998).

For building frames:

for $n \leq 4$ :

4 s $\mathbf{n}<20$ :

n 220 :

$$
\Delta_{\mathbf{i}}=\theta_{\mathbf{d}} \mathbf{h}_{\mathbf{i}}
$$

where $\mathrm{n}$ is the number of storeys.

For cantilever wall buildings, the critical drift occurs at the top of the building. From Equation 2(d), assuming a linear distribution of curvature with height,

and hence Equation 15 becomes:

$$
\theta_{\mathrm{y}}=1.0 \varepsilon_{\mathrm{y}} \mathrm{h}_{\mathrm{n}} / 1_{\mathrm{w}}
$$

$$
\theta_{d}=1.0 \varepsilon_{y} h_{m} / \ell_{w}+\left(\phi_{m}-\phi_{y}\right) \ell_{p} \leq \theta_{c}
$$


Analyses of typical wall sections (Priestley and Kowalski, 1998) indicated that, for given limit strains, the limit state curvature is rather insensitive to axial load and reinforcement ratios. For example, it was found that the damage-control limit state curvature based on limit strains of $\varepsilon_{\mathrm{cm}}=0.018$ and $\varepsilon_{\mathrm{sm}}=0.06$ could be expressed as:

The plastic drift, $\theta_{\mathrm{p}}$, can then be expressed as

$$
\varphi_{\mathrm{m}}=0.073 / \mathrm{w}_{\mathrm{w}} \pm 10 \%
$$

$$
\theta_{p}=\left(\phi_{m}-\phi_{y}\right) l_{p}
$$

where $\varphi_{y}$ is given by Equation 2(d), and the plastic hinge length $l_{p}$ may be taken as the larger of:

$$
\begin{gathered}
\mathrm{l}_{\mathrm{P}}=0.2 \mathrm{l}_{\mathrm{w}}+0.03 \mathrm{~h}_{\mathrm{n}} \\
\mathrm{l}_{\mathrm{P}}=0.054 \mathrm{~h}_{\mathrm{n}}+0.022 \mathrm{f}_{\mathrm{y}} \mathrm{d}_{\mathrm{b}}
\end{gathered}
$$

where $h_{n}$ is the roof height, and $d_{b}$ and $f_{y}$ are the diameter and yield stress of the wall vertical reinforcement (Paulay and Priestley, 1992).

The design displacement profile is thus:

$$
\Delta_{i}=\Delta_{d i}+\Delta_{p i}=\frac{2}{3} \varepsilon_{y} \frac{h_{i}^{2}}{l_{w}}\left(1.5-\frac{h_{i}}{2 h_{w}}\right)+\left(\theta_{d}-\frac{\varepsilon_{g} h_{\mathrm{q}}}{l_{w}}\right)\left(h_{i}-\frac{l_{p}}{2}\right)
$$

Having found the design displacement profile from Equation 18 or 24 for frames and walls, respectively, the design displacement for the equivalent SDOF system is:

$$
\Delta_{d}=\sum_{i=1}^{n}\left(m_{i} \Delta_{i}^{2}\right) / \sum_{i=1}^{n}\left(m_{i} \Delta_{i}\right)
$$

where $m_{i}$ are the storey masses.

\subsubsection{Effective Mass}

From consideration of mass participation in the fundamental mode, the effective system mass for the equivalent SDOF system is:

$$
\mathbf{m}_{\mathrm{a}}=\sum_{\mathrm{i}=1}^{\infty}\left(\mathrm{m}_{\mathrm{i}} \Delta_{\mathrm{i}}\right) / \Delta_{\mathrm{d}}
$$

Note that this will differ slightly from the mass participating in the first elastic mode, since it is the inelastic model shape that is used. Typically:

$$
\mathrm{m}_{\mathrm{e}} \approx 0.7 \Sigma \mathrm{m}_{\mathrm{i}}
$$

\subsubsection{Effective Damping}

The effective damping depends on the structural system and ductility, as illustrated in Figure 6(c). Thus an estimate is needed of the ductility before the design proceeds. This is straightforward, since the work described earlier in this paper establishes that the dimensionless yield curvatures of concrete structural systems are 
independent of strength. Note that the same conclusion is also obviously valid for steel members : the yield curvature can be expressed as:

$$
\varphi_{\mathrm{y}}=2 \varepsilon_{\mathrm{y}} / \mathrm{h}_{\mathrm{b}}
$$

regardless of the width or depth of the flanges, within normal limits of steel sections.

The yield displacement at the height of the resultant lateral seismic force may thus be found, with adequate accuracy as follows:

$$
\begin{array}{ll}
\text { Walls: } & \Delta_{y}=\frac{2 \varepsilon_{y}}{3 \ell_{w}}\left(0.7 h_{w}\right)^{2} \\
\text { Frames: } & : \Delta_{y}=0.5 \varepsilon_{y}\left(\frac{l_{b}}{h_{b}}\right)\left(0.6 h_{b}\right)
\end{array}
$$

Where the height of the resultant lateral force is approximately as $0.7 h_{n}$ and $0.6 h_{n}$ for wall and frame structures, respectively. Although these heights are adequate for regular structures, a more precise determination of effective height should be made when mass or storey heights vary significantly with height. In this case, the effective height $h_{c}$ should be taken as:

$$
h_{e}=\sum_{i=1}^{n}\left(m_{i} \Delta_{i} h_{i}\right) / \sum_{i=1}^{n}\left(m_{i} \Delta_{i}\right)
$$

The ductility can now be determined from:

$$
\mu_{\mathrm{s}}=\Delta_{\mathrm{d}} / \Delta_{\mathrm{y}}
$$

where $\Delta_{d}$ is given by Equation 25 . The effective damping can then be read from the appropriate ductility/damping curve (eg, Figure 6(c)).

When the lateral resistance of a building in a given direction is comprised of a number of walls of different lengths, the ductility demand of each wall will differ, since the yield displacements of the walls are inversely proportional to wall length (Equation 29a), while the maximum displacements will be essential equal, subject only to small variations resulting from torsional response. Hence the system damping will need to consider the different effective damping in each wall. A weighted mean average is appropriate, given by:

$$
\xi_{e}=\sum_{j=1}^{m}\left(V_{j} \xi_{j}\right) / \sum_{j=1}^{m} v_{j}
$$

where $V_{j}$ and $\xi_{j}$ are the base shear and damping of the $m$ walls in a given direction. A rational design decision will be to apportion the base shear between the walls in proportion to the wall length squared. This will result in essentially constant reinforcement ratios between walls. Hence, Equation 32 can be rewritten:

$$
\xi_{0}=\sum_{j=1}^{\infty}\left(\ell_{w j}^{2} \xi_{j}\right) / \sum_{j=1}^{m} e_{w j}^{2}
$$

Note that conventional force based design would apportion the base shear between walls in proportion to the cube of the wall length, based on the invalid assumption that the walls could be made to achieve simultaneous yield. The consequence is that the longer walls end up more heavily reinforced that the shorter walls, which is irrational, and results in further imbalance in elastic stiffness.

Having determined the design displacement, effective mass and effective damping, and hence the effective period (eg, from Fig. 6(d)) the required design base shear is found using Equations 5 and 6. 


\subsubsection{Distribution of Base Shear}

The base shear calculated in accordance with the above procedure should be vertically distributed in proportion to the vertical mass and displacement profiles. Thus:

$$
F_{i}=V_{B}\left(m_{i} \Delta_{i}\right) / \sum_{i-1}^{n}\left(m_{i} \Delta_{i}\right)
$$

Similarity with force-based design will immediately be apparent. The difference is that the actual displacement profile, rather than a height-proportional displacement, is adopted. No additional force at the roof level is recommended. When capacity design principles are adopted (see below) and normal gravity load requirements for upper levels are enforced, it is rare to find excessive ductility demand developing at the upper floor levels under inelastic time history analyses (Loeding et al, 1998).

\section{BUILDING ANALYSIS FOR DESIGN MOMENTS}

In order to determine the design moments at potential plastic hinge location, the lateral force analysis of the structure under the force vector represented by Equation (34) should be based on member stiffnesses representative of conditions at maximum displacement response. This is an essential component of the substitute structure approach. (Shibata and Sozen, 1976). For cantilever wall buildings this can be simplified to distribution of the forces between walls in proportion to 18 , as suggested above, with the walls then analysed separately.

However, for frame and dual system buildings, more care is needed. With frame buildings, the member stiffness should reflect the effective stiffness at maximum response, rather than the elastic cracked-section stiffness $\mathrm{I}_{\mathrm{cr}}$ usually adopted for force-based analysis. With a weak-beam/strong-column design, beam members will be subjected to inelastic actions, and the appropriate stiffness will be:

$$
\mathrm{I}_{\mathrm{b}}=\mathrm{I}_{\mathrm{cr}} / \mu_{\mathrm{b}}
$$

where $\mu_{b}$ is the expected beam displacement ductility demand. Analyses have shown that member forces are not particularly sensitive to the level of stiffness assumed, and thus is it acceptable to assume $\mu_{\mathrm{b}}=\mu_{\mathrm{s}}$, the frame design ductility.

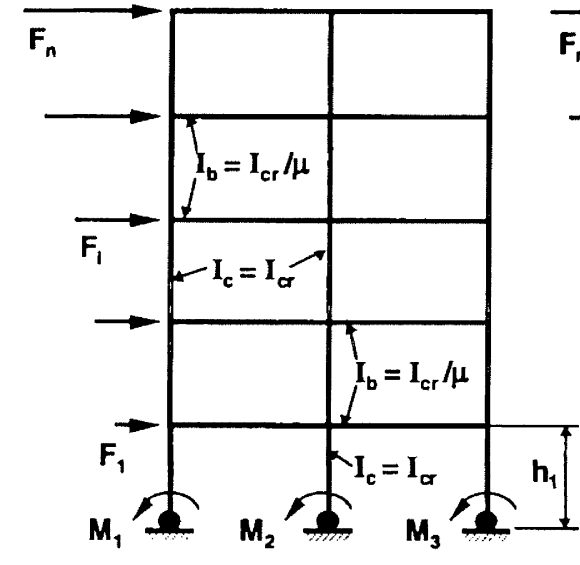

(a)
Frame Building

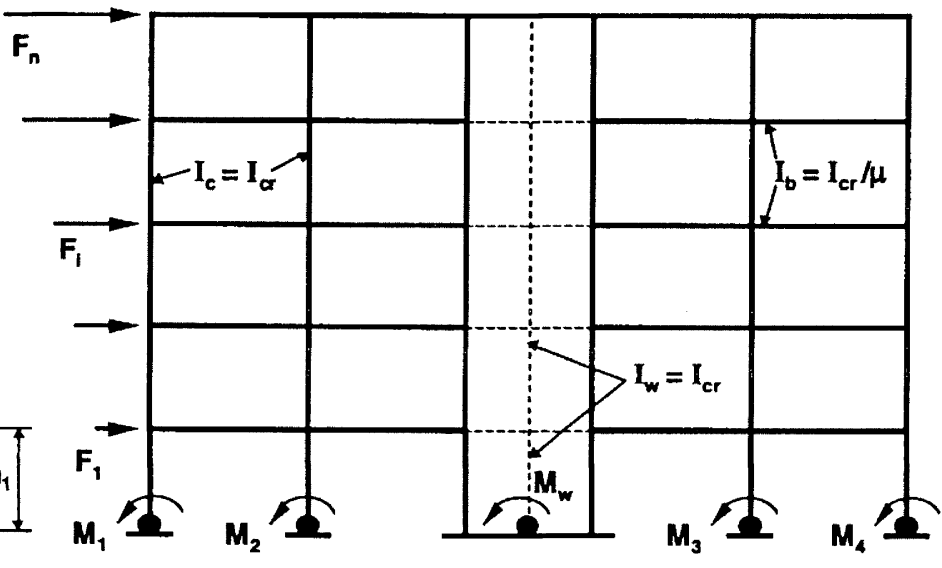

(b) Dual System

Figure 9: Member Stiffnesses for Substitute Structure Analyses

Since the columns will be protected against inelastic action by capacity design procedures, their stiffness should be $I_{\mathrm{cr}}$, with no reduction for ductility. An exception exists for the ground floor column, where plastic hinges will normally be expected at the base level, but not at first floor level. It has been found (Loeding et al, 1998) that 
the most effective way to model this is to place a hinge at the base level and apply a base resisting moment $M_{b}$ to the hinge, while representing the column by the elastic cracked-section stiffness. This is illustrated in Figure 9(a). The values of $M_{b}$ placed at the base hinges are, to some extent, the designers choice, since analysis of the structure under the lateral force vector together with the chosen column base moments $M_{b}$ will ensure a statically admissible equilibrium solution for design moments. In fact this freedom, implying some moment redistribution between beam hinges and column base hinges, allows the designer to improve the structural efficiency. A common choice will be to choose base moments such that the point of contraflexure in the lower storey columns occurs between $55 \%$ and $65 \%$ of the storey height above the base, thus ensuring capacity protection against hinging at the top of the ground floor columns, and an advantageous distribution of moments above and below the first level beams.

With a point of contraflexure chosen at $60 \%$ of the column height $h_{1}$ (to beam centreline) and with reference to Figure 9(a) equilibrium requires that:

$$
\Sigma M_{b}=M_{b 1}+M_{b 2}+M_{b 3}=V_{b}\left(0.6 h_{1}\right)
$$

Assuming $h_{b}=0.15 h_{1}$, the column moments at the base of the first floor beams will be $54 \%$ of those at the column base, providing adequate protection for increased column moment resulting from strain hardening and higher mode effects. Strictly, the distribution of $\Sigma M_{b}$ between the three columns in Figure 8(a) should reflect the variation in column stiffness caused by the seismically induced axial loads. Thus less moment should be resisted at column 1 than at column 3. However, analyses have shown that satisfactory designs result when the stiffness of the column is based on the gravity loads alone, with $\Sigma \mathrm{M}_{\mathrm{b}}$ resisted by equal moments $\mathrm{M}_{1}$ and $\mathrm{M}_{2}$ (Loeding et al, 1998).

With dual systems consisting of walls and frames (Figure 8(b)), force-based design based on elastic analyses are found to have the wall dominating behaviour in the lower levels, and the frame dominating behaviour in the upper storeys. (Paulay and Priestley, 1992). A substitute structure analysis representing conditions at maximum displacement response is likely to result in significantly different distribution of actions between walls and frames. In the substitute structure analysis, the wall stiffness will be reduced over the lower levels in proportion to the expected ductility demand, implying more force transfer to the frames. At the upper levels the wall will be expected to remain elastic, while the beam hinges will reduce the effective stiffness of the frames, transferring forces to the wall. Although not yet confirmed by static and dynamic analysis it would appear that a direct displacement-based procedure would result in a more rational distribution of design actions compared with force-based approaches. More research is needed in this area.

\section{SOME IMPLICATIONS OF PERFORMANCE BASED SEISMIC DESIGN}

\subsection{Incorporation of Foundation Flexibility Effects into Performance Based Seismic Design}

The incorporation of foundation compliance effects into force-based design is generally carried out inadequately, if at all. Consider the cantilever structural wall building of Fig. 10. Foundation flexibility will increase the displacement at nominal strength $V_{n}$ from $\Delta_{y}$ to $\left(\Delta_{y}+\Delta_{f}\right)$ where $\Delta_{y}$ is the structural displacement for a rigid base, and $\Delta_{\mathrm{f}}$ is the displacement due to foundation flexibility. This will increase the elastic period by the ratio:

$$
\mathrm{T}_{\mathrm{f}}=\mathrm{T}_{\mathrm{r}} \sqrt{\frac{\Delta_{\mathrm{y}}+\Delta_{\mathrm{f}}}{\Delta_{\mathrm{y}}}}
$$

Generally this will imply reduced seismic design forces. However, it is not always recognised that the ductility capacity is also reduced. With respect to Fig. 10(b), the plastic rotation capacity of the wall base hinge will be unaffected by the foundation flexibility, and hence the plastic displacement $\Delta_{p}$ will be the same for both rigid and flexible base conditions. The displacement ductility capacity will then reduce from:

rigid base:

flexible base:

$$
\mu_{\Delta r}=1+\Delta_{\mathrm{p}} / \Delta_{\mathrm{y}}
$$

$$
\mu_{\Delta f}=1+\Delta_{p} /\left(\Delta_{g}+\Delta_{\sharp}\right)
$$




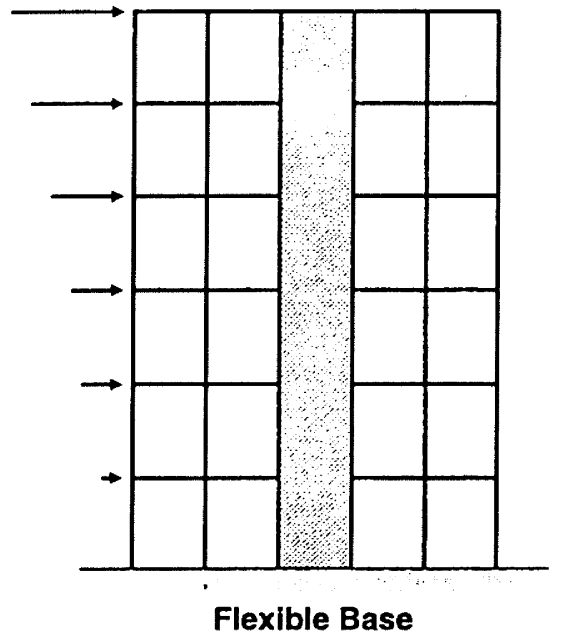

(a) Building

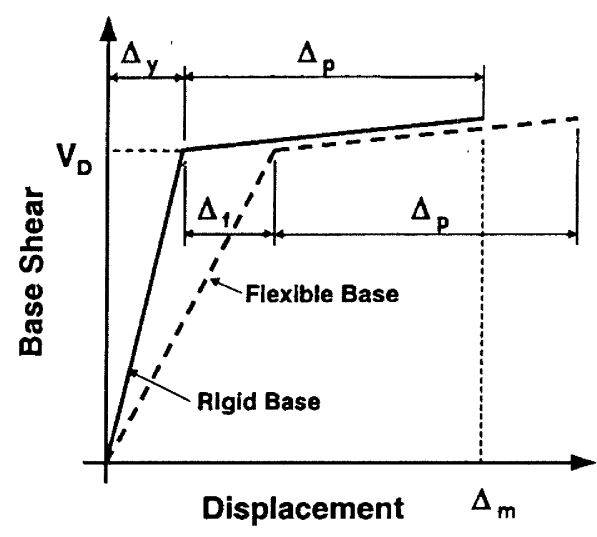

(b) Lateral Force-Displacement

Figure 10: Influence of Foundation Rotation on Displacement Ductility Capacity

However, if the maximum displacement $\Delta_{\mathrm{m}}$ is limited by code maximum drift limitations, the design ductilities for the two cases will be:

$$
\begin{array}{ll}
\text { rigid base: } & \mu_{\Delta r}=1+\left(\Delta_{m}-\Delta_{y}\right) / \Delta_{y} \\
\text { flexible base: } & \mu_{\Delta f}=1+\left(\Delta_{m}-\Delta_{y}-\Delta_{f}\right) /\left(\Delta_{y}+\Delta_{f}\right)
\end{array}
$$

In both cases the foundation flexibility implies reduced available displacement ductility, and hence reduced force-reduction factors.

Although both influences (period increase; ductility decrease) can be incorporated in force-based design they rarely are. It is also clear however that an additional influence - that of soil damping should also be considered. It is not obvious how this should be included in force-based design, but it is comparatively straight-forward for direct displacement-based design.

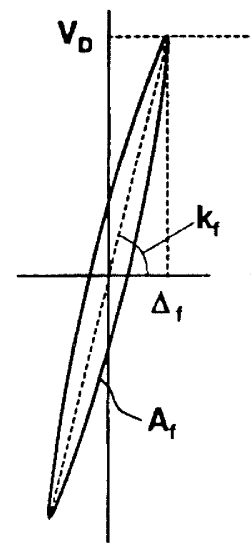

(a) Foundation

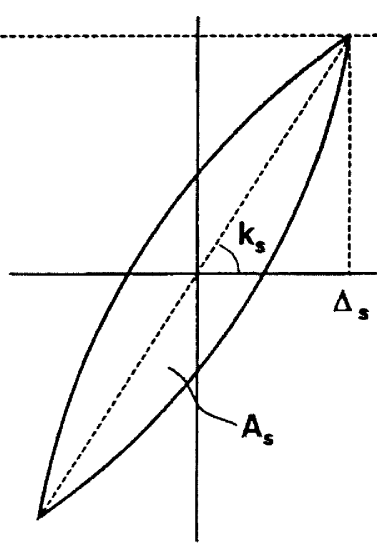

(b) Structure

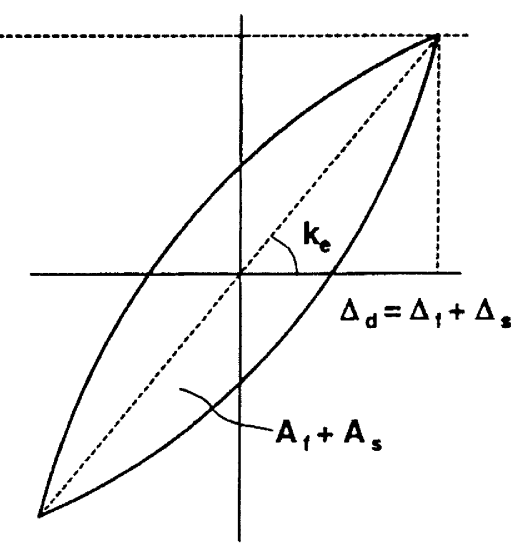

(c) Foundation + Structure

Figure 11: Incorporation of Foundation Flexibility into Direct Displacement-Based Design

Consider the lateral force-displacement hysteresis loops of Fig. 11, where foundation and structure components at peak design displacement response $\Delta_{\mathrm{d}}$ have been separated. The design displacement could be limited by code drift limits or by a structural strain-based limit displacement $\Delta_{\mathrm{s}}=\Delta_{\mathrm{m}}$.

The equivalent viscous damping for the foundation and for the structure can be separately expressed as: 
$\begin{array}{ll}\text { foundation: } & \xi_{\mathrm{f}}=\frac{\mathrm{A}_{\mathrm{f}}}{2 \pi \mathrm{V}_{\mathrm{D}} \Delta_{\mathrm{f}}} \times 100 \% \\ \text { structure: } & \xi_{\mathrm{s}}=\frac{\mathrm{A}_{\mathrm{s}}}{2 \pi \mathrm{V}_{\mathrm{D}} \Delta_{\mathrm{d}}} \times 100 \%\end{array}$

Where $A_{f}$ and $A_{s}$ are hysteretic areas [ie, energy absorbed] for foundation and structure respectively. As shown in Fig. 11(c), the hysteretic areas of the combined structure/foundation system will be additive, and hence the system equivalent viscous damping will be:

$$
\xi_{\mathrm{e}}=\frac{\xi_{\mathrm{f}} \Delta_{\mathrm{f}}+\xi_{\mathrm{s}} \Delta_{\mathrm{s}}}{\Delta_{\mathrm{f}}+\Delta_{\mathrm{s}}}
$$

Design then proceeds in the normal fashion determining the period from the displacement spectra set, or more directly from Equation 14, and hence the effective stiffness $k_{e}$ from Equation 5 and the design shear $V_{D}=V_{B}$ from Equation (6).

\subsection{Influence of Seismic Intensity on Base Shear}

Force-based and Direct displacement-based design procedure imply significantly different structural sensitivity to seismic intensity. This can be illustrated with reference to Fig. 12, where acceleration spectra (Fig. 12a) and displacement spectra (Fig. 12b) are shown for two seismic zones. It is assumed that the spectral shapes for the two zones are identical and each are found by multiplying a base level spectrum by the zone factor $Z_{1}$ or $Z_{2}$.

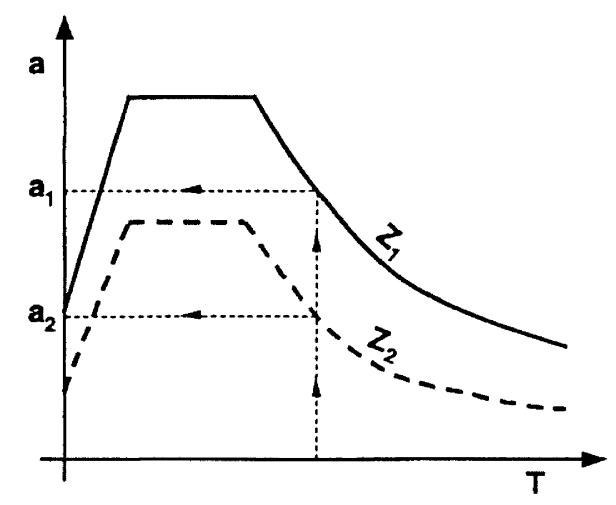

(a) Acceleration Spectra

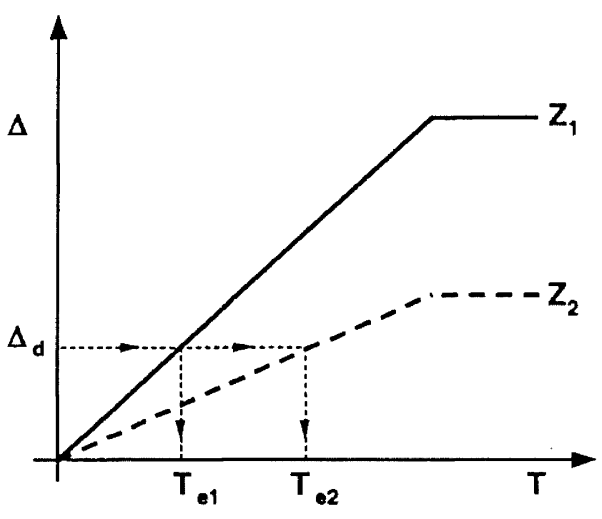

(b) Displacement Spectra

Figure 12: Influence of Zone Intensity on Design Actions

Assume the structural geometry of the designed building is the same for the $Z_{1}$ and $Z_{2}$ zones. Then, for forcebased design, making normal design assumptions that the elastic period is the same for the two buildings, it is clear that the required base shear forces, $\mathrm{V}_{\mathrm{b} 1}$ and $\mathrm{V}_{\mathrm{b} 2}$, for the two buildings are related by

$$
\mathrm{V}_{\mathrm{b} 2}=\mathrm{V}_{\mathrm{b} 1} \frac{\mathrm{Z}_{2}}{\mathrm{Z}_{1}}
$$

Under direct displacement-based design, the assumption of equal geometry ensures that the yield displacements, and the limit-state design displacements for the two buildings are identical. Hence the ductility, and the damping, is also the same for the two buildings. As may be seen from Fig. 12b, with equal design displacement and damping the effective periods $\mathrm{Te}_{1}$ and $\mathrm{Te}_{2}$ will be related to the zone intensity by: 


$$
\mathrm{T}_{\mathrm{e} 2}=\mathrm{T}_{\mathrm{e} 1} \frac{\mathrm{Z}_{1}}{\mathrm{Z}_{2}}
$$

From Equation 5, the required effective stiffnesses are inversely proportional to the period squared, hence:

$$
K_{22}=K_{11}\left(\frac{Z_{2}}{Z_{1}}\right)^{2}
$$

Further, since the design displacements are equal, Equation (6) yields the base shear ratio as:

$$
V_{B 2}=V_{B 1}\left(\frac{z_{2}}{Z_{1}}\right)^{2}
$$

Thus the required strength is proportional to the square of the seismic intensity. This is a fundamentally important difference between the two approaches, particularly for regions of low seismicity.

\subsection{Influence of Building Height}

A further finding of some interest can be obtained by examining the sensitivity of base shear to building height. We assume for simplicity that the section dimensions of structural members are not affected by the building height, and that the design deflected shape is also independent of building height. Clearly this latter assumption will become increasingly crude as the height increases. Let $\mathrm{n}=$ number of storeys, with constant mass $\mathrm{m}$ per storey. $\mathrm{k}_{1}$ to $\mathrm{k}_{6}$ in the following are constants.

$$
\begin{array}{ll}
\text { Effective mass: } & \mathrm{m}_{\mathrm{e}}=\mathrm{k}_{1} \mathrm{~nm} \\
\text { Effective displacement: } & \Delta_{\mathrm{d}}=\mathrm{k}_{2} \mathrm{n}
\end{array}
$$

Effective damping will be independent of $\mathrm{n}$, since yield drift and code drift limit (and hence displacement ductility) are independent of strength.

Provided the design displacement $\Delta_{d}$ given by Equation $46(\mathrm{~b})$ is less than the displacement at peak period (eg, $T_{e}$ $=4 \mathrm{sec}$, Fig. 8 ), the effective period will thus be:

$$
\mathrm{T}_{\mathrm{e}}=\mathrm{k}_{3} \Delta_{\mathrm{d}}=\mathrm{k}_{2} \mathrm{k}_{3} \mathrm{n}
$$

From Equation (5), effective stiffness

$$
k_{0}=\frac{4 \pi^{2} m_{0}}{T_{*}^{2}}=\frac{k_{4} k_{1} n m}{\left(k_{2} k_{3}\right)^{2} n^{2}}=k_{3} m / n
$$

From Equations (6), 46(b) and (46d) the design base shear will be:

$$
\mathrm{V}_{\mathrm{B}}=\mathrm{k}_{\mathrm{e}} \Delta_{\mathrm{d}}=\mathrm{k}_{5} \mathrm{~m} / \mathrm{n} \times \mathrm{k}_{2} \mathrm{n}=\mathrm{k}_{6} \mathrm{~m}
$$

Thus Equation 46(e) implies that the design base shear force is independent of the number of storeys. This might seem to point the way towards possible design simplification.

\subsection{Influence of Seismic Characteristics - The So-Called Fling Effect}

Recent concerns about the effects of high-velocity pulses recorded in recent earthquakes (eg, Northridge, 1994, Kobe, 1995] on structural ductility demand, have led to requirements for reduced force-reduction factors for structures in potential near-field environments. This is because damping (whether elastic or hysteretic) is less effective in reducing displacements under a pulse-type loading than under multi-cycle input. In direct displacement-based design this requires provision of displacement response spectra specifically computed for fling type earthquakes. In such spectra, the lines for different levels of damping are closer together than implied 
by Equation 10. Use of such spectra directly require higher base-shear strength for ductile systems than would be required for more conventional spectra. It is contended that this is a more direct way of accounting for seismic characteristics than use of a $5 \%$ elastic acceleration spectrum, with reduced force-reduction factor.

\section{CONCLUSIONS}

There is currently an intensive examination of the implications of performance limit states to seismic design of structure. In the current debate, most suggested design procedures require the addition of a displacement, or damage, check to an essentially force-based design procedure. These approaches have the advantage of retaining familiar design steps, and have been implemented in some design procedures for many years.

An alternative approach based on designing to achieve a specified strain or drift performance level under a specified seismic intensity has been developed. It was shown that this is very simple to apply and should result in uniform levels of seismic risk. Significant differences in seismic performance can be expected from structures designed to this approach when compared with conventional force-based/displacement-check approaches. In particular, design for inclusion of foundation compliance, for non-standard hysteretic characteristics, and for variation in seismic intensity are treated in a rational manner not feasible with current procedures.

Although not specifically considered in this paper, due to space limitations, the rational approach to torsional response of ductile structures developed by Paulay (Paulay 1997) can readily be incorporated in direct displacement-based design.

It is emphasised that the key merits of the design method are simplicity and rationality. The method has already achieved some acceptance, being advocated by the Structural Engineering Association of California for the 1999 "Blue Book" and as an alternative seismic design procedure for the draft Australia/New Zealand seismic design code.

\section{ACKNOWLEDGMENTS}

The collaborative efforts of numerous researchers in developing direct displacement-based design are acknowledged. Of particular importance are the contributions of Professor M J Kowalski and Professor G M Calvi. Financial assistance of the University of California, San Diego and the New Zealand Earthquake Commission is gratefully acknowledged.

\section{REFERENCES}

ATC, 1996:ATC32, "Improved seismic design guidelines for bridges", Applied Technology Council, Redwood City, 1996.

Bertero, V.V and Zagajeshi, S.W. (1979) "Optimal inelastic design of seismic resistance reinforced concrete framed structures", in "Nonlinear Design of Concrete Structures". Proc International Symposium, University of Waterloo, Canada, pp219-272.

CEB (1997) Bulletin 279 "Seismic Design of Structures", CEB, Paris, 1997.

Cosenza E. and Manfredi G. "The improvement of the seismic-resistant design for existing and new structures using damage concept" in Fajfar P. and Krawinkler, H (Eds) (1997), "Seismic Design Methodologies for the Next Generation of Codes". Proceedings of International Conference at Bled, Slovenia. A.A. Balkema, Rotterdam/Brookfield, 1997, pp119-130.

EC8, (1994) "Eurocode 8 : Design Provisions for earthquake resistance of structures".

Fajfar P. and Krawinkler, H (Eds) (1997), "Seismic Design Methodologies for the Next Generation of Codes". Proceedings of International Conference at Bled, Slovenia. A.A. Balkema, Rotterdam/Brookfield, 1997, 411 pp.

Fajfar, P., Gaspersic, P. and Drobnic, D. (1997) "A simplified nonlinear method for seismic damage analysis of structures" in Fajfar P. and Krawinkler, H (Eds) (1997), "Seismic Design Methodologies for the Next Generation 
of Codes". Proceedings of International Conference at Bled, Slovenia. A.A. Balkema, Rotterdam/Brookfield, 1997, pp183-194.

Fajfar, P. (1998) "Capacity Spectrum Method based on Inelastic Demand Spectra". IKPIR Report EE-3/98, University of Ljubljana, Slovenia, $12 \mathrm{pp}$.

Fardis, M.N. and Panagiotakos, T.B. "Displacement-based design of RC Buildings : Proposed approach and applications" in Fajfar P and Krawinkler, p195-206.

Fintel, M. and Ghosh, S.K. (1982) "Explicit inelastic dynamic design procedure for aseismic structures", Journal ACI 79, 2, p110-118.

Freeman, S.A. (1998) "Development and Use of Capacity Spectrum Method" Proc. $6^{\text {th }}$ US National Conference on Earthquake Engineering, Seattle, 12pp.

Hatamoto, H., Chung, Y.S. and Shinozuka, M. (1990) "Seismic Capacity Enhancement of RC Frames by Means of Damage Control Design”, Proc., 4 USNCEE (Palm Springs, CA), 2, p279-288.

JRA (1996), Japan Road Association, "Design specifications of highway bridges, part I common part, part II steel bridges, part III concrete bridges, part IV foundations and part V seismic design.

Kappos, A.J. (1997) "Partial inelastic analysis procedure for optimum capacity design of RC buildings" in Fajfar, P and Krawinkler, H (Eds) (1997), "Seismic Design Methodologies for the Next Generation of Codes". Proceedings of International Conference at Bled, Slovenia. A.A. Balkema, Rotterdam/Brookfield, 1997, pp229240.

Kawashima, K (1997) "The 1996 Japanese Seismic Design Specifications of Highway Bridges and the Performance Based Design" in Fajfar P. and Krawinkler, H (Eds) (1997), "Seismic Design Methodologies for the Next Generation of Codes". Proceedings of International Conference at Bled, Slovenia. A.A. Balkema, Rotterdam/Brookfield, 1997, pp 371-382.

Kowalsky M.J. and Priestley, M.J.N. (1995)

Loeding, S. Kowalsky, M.J. and Priestley, M.J.N. (1998) "Displacement-based design methodology applied to R.C. Building frames". Report SSRP 98/06 Structures Department, UCSD, 296pp.

Moehle J.P. (1992), "Displacement-Based design of RC structures subjected to earthquakes", Earthquake Spectra 3, 4, pp403-428.

OES, 1995 : California Office of Emergency Services "Vision 2000:Performance Based Seismic Engineering of Buildings", Prepared by Structural Engineers Association of California, Sacramento, CA 1995.

Otani, S. (1997), "Development of Performance-based Design Methodology in Japan" in Fajfar P. and Krawinkler, H (Eds) (1997), "Seismic Design Methodologies for the Next Generation of Codes". Proceedings of International Conference at Bled, Slovenia. A.A. Balkema, Rotterdam/Brookfield, 1997, pp59-68.

Park R. and Paulay T (1975), Reinforced Concrete Structures, John Wiley \& Sons. New York, 769 p.

Paulay, T. (1997) "A behaviour-based design approach to earthquake-induced torsion in ductile buildings" In Fajfar P. and Krawinkler, H (Eds) (1997), "Seismic Design Methodologies for the Next Generation of Codes". Proceedings of International Conference at Bled, Slovenia. A.A. Balkema, Rotterdam/Brookfield, 1997, pp289-298.

Paulay, T. and Priestley, MJN (1992) "Seismic Design of Reinforced Concrete and Masonry Buildings", John Wiley and Sons, New York, $744 \mathrm{p}$.

Poland, C.D. and Hom, D.B. (1997), "Opportunities and Pitfalls of Performance-based Seismic Engineering" in Fajfar P. and Krawinkler, H (Eds) (1997), "Seismic Design Methodologies for the Next Generation of Codes". Proceedings of International Conference at Bled, Slovenia. A.A. Balkema, Rotterdam/Brookfield, 1997, pp 6978. 
Priestley, M.J.N. (1993) "Myths and Fallacies in Earthquake Engineering - Conflicts Between Design and Reality.", Bull. NZNSEE, 26, 3, pp329-341.

Priestley, M.J.N. (1998(a)), "Displacement-Based Approaches to Rational Limit States Design of New Structures". Keynote Address, Proc. 11 European Conf. Earthquake Engineering, Paris.

Priestley, M.J.N. (1998(b)) "Brief Comments on Elastic Flexibility of Reinforced Concrete Frames and Significance to Seismic Design” Bull. NZNSEE 31, 4.

Priestley, M.J.N. and Calvi, G.M. (1997) "Concepts and Procedures for Direct Displacement-Based Design and Assessment". In Fajfar P. and Krawinkler, H (Eds) (1997), "Seismic Design Methodologies for the Next Generation of Codes". Proceedings of International Conference at Bled, Slovenia. A.A. Balkema, Rotterdam/Brookfield, 1997, p171-182.

Priestley, M.J.N. and Kowalski, M.J. (1998) "Aspects of Drift and Ductility Capacity of Cantilever Structural Walls" Bulletin, NZNSEE 31, 2.

Priestley, M.J.N. and Kowalsky, M.J. (2000) "Direct displacement-based seismic design of concrete buildings". Bull. NZSEE, (in press).

Priestley M.J.N. and Park R. (1987), "Strength and ductility of RC Bridge Columns Under Seismic Loading", Structural Journal ACI, 84, 1, pp285-336.

Priestley, M.J.N., Seible, F. and Calvi, G-M (1996) "Seismic Design and Retrofit of Bridges", John Wiley and Sons, New York, $686 \mathrm{p}$.

SANZ (1992) NZS4203 "Code of Practice for General Structural Design and Design Loadings for Buildings", NZ Standards Association, Wellington.

SEAOC (1999) "Guidelines for performance-based seismic engineering", SEAOC Blue Book - draft of Appendix I.

Shibata, A. and Sozen, M. (1976) "Substitute structure method for seismic design in reinforced concrete". Jour. Str. Div. ASCE, 102, 6 .

Stone, W.C. and Taylor, A.W. (1994) "ISDP:Integrated approach to seismic design of reinforced concrete structures", Jour. Str. Eng. ASCE. 120, 12, p3548-3566.

UBC (1997) Uniform Building Code. International Conference of Building Officials, Whittier, Ca. 